\title{
NUMERICAL INVESTIGATION OF THERMAL COMFORT IN AN ISOLATED FAMILY HOUSE UNDER NATURAL CROSS-VENTILATION
}

\author{
SHERZAD HAWENDI ${ }^{1} \&$ SHIAN GAO $^{2}$ \\ ${ }^{1}$ Department of Engineering, University of Leicester, United Kingdom \\ ${ }^{2}$ University of Sulaimani, Sulaimani, Kurdistan Region, Iraq
}

\begin{abstract}
Thermal comfort for naturally ventilated buildings mainly depends on parameters such as the outside weather, building configuration and neighborhood effects. Even though most research works include studies on indoor thermal comfort coupled with outdoor conditions, they are generally limited to singlesided ventilation. In addition, only a very few such investigations employ the human thermal comfort index (PMV) in the analysis of the indoor environment, which is generally held to be more realistic than other indices. Simulations using computational fluid dynamics (CFD) have been carried out for the wind-driven natural ventilation (for a cooling purpose) of a residential building with two inlet openings to understand the relationship between the wind speed and human thermal sensation index. The numerical model is validated against available experimental data. The CFD results show that human thermal comfort is significantly affected by the wind speed, and this factor can be more active in this type of building if the wind has a relatively high speed.
\end{abstract}

Keywords: natural ventilation, thermal comfort, computational fluid dynamics (CFD), wind speed.

\section{INTRODUCTION}

Natural ventilation has been widely used in buildings due to the potential for energy savings and indoor air quality promotion it represents. Designing naturally ventilated buildings is thus particularly important to both engineers and architects. The successful design of natural ventilation systems in buildings should be balanced against three factors: indoor air quality, thermal comfort, and energy consumption [1], [2]. Thermal comfort can be defined as a state of mind that whereby one is satisfied with the thermal environment and can be maintained by dissipating the heat generated from the body produced by metabolic activity, thereby maintaining thermal equilibrium with the surrounding [3]. In hot climates, the best way to reduce the heat so generated, in addition to that generated by appliances inside buildings, is natural ventilation. Natural ventilation depends on the outside climatic conditions (wind speed, wind direction and temperature), building features (building form, dimension, shape and size of openings), and construction methods [4]-[6]. There have been numerous indoor thermal environmental studies conducted for various type of buildings, for instance, public buildings and transportation, whole building environments and offices.

Hassan et al. [7], studied the effects of window combination on the thermal comfort indexPredicted Mean Vote (PMV) for various wind speeds and directions. This study showed that two non-adjacent openings in single-sided ventilation give better ventilation than adjacent openings. The effect of three opening configurations on natural ventilation for residential units in Hong Kong was studied by Gao and Lee [8]. This study concluded that a high natural ventilation rate can be achieved when the two openings are positioned perpendicular to each other or in opposite directions. Stavrakakis et al. [9], upgraded the window opening configuration for thermal comfort in buildings in hot climates employing natural ventilation by using a new artificial technique, with the results of their study showing that the proposed procedure gives the ideal window plans, which compares to the best target variables. 
Koranteng et al. [10], investigated the impact of opening locations and size on indoor comfort for residential rooms with natural single-sided ventilation, whose study showed that to achieve comfortable indoor conditions the ideal window-to-wall ratio should be between $10 \%$ to $40 \%$; furthermore, the positions of the windows did not seem to have any effect on the indoor temperature values. Prakash and Ravikumar [3], introduced a new set of strategies to locate window opening positions by analyzing thermal comfort in a residential building room using generalized window opening positions on adjacent walls.

Indoor thermal comfort is determined by various factors in the current study, with Predicted Mean Vote (PMV) being one such factor considered. Occupants can control their indoor thermal environment by clothing, operable windows, fans or heaters, and sun shades. ASHRAE Standard 55 uses the PMV index to set the requirements for the indoor thermal comfort, and it predicts the mean value of the votes for a large group of subjects for a particular combination of air and radiant temperature, clothing insulation, metabolic rate, air speed, and relative humidity. Standard thermal comfort surveys ask subjects about their impression as to their thermal sensation on a seven-point scale of cold $(-3)$ to hot $(+3)$, where zero is the ideal value with recommended limits between $(-0.5)$ and $(0.5)$ [11]. The extended thermal comfort index ePMV was used for the current study and can be determined by multiplying the PMV from Finger's Equation by an expectancy factor $(e)$. The mathematical expression of Fingers' PMV model is as given by eqn. (1) below [12]:

$$
\begin{aligned}
& P M V=e\left[0.303 e^{-0.036 M}+0.028\right]\{(M-W) \\
&-3.96 E^{-8} f_{c l}\left[\left(t_{c l}+273\right)^{4}-\left(t_{r}+273\right)^{4}\right]-f_{c l} h_{c}\left(t_{c l}-t_{a}\right) \\
&-3.05\left[5.73-0.007(M-W)-p_{a}\right]-0.42[(M-W)-58.15] \\
&\left.-0.0173 M\left(5.87-p_{a}\right)-0.0014 M\left(34-t_{a}\right)\right\},
\end{aligned}
$$

where $t_{C l}\left({ }^{\circ} \mathrm{C}\right)$ is the surface temperature of clothing, $t_{r}\left({ }^{\circ} \mathrm{C}\right)$ is the mean radiant temperature, $f_{c l}$ is the clothing area factor, $p_{a}(\mathrm{kPa})$ is the partial water vapor pressure and $h_{c}\left(\mathrm{~W} / \mathrm{m}^{2} \mathrm{C}\right)$ is the convective heat transfer coefficient between the occupant and the environment. Based on Eq. 1, the thermal comfort index of the space was determined from Table 1, and for comparison purposes the appropriate range for ePMV was taken as being between $(-0.5$, $0.5)$ and $(-1,1)$, in which $90 \%$ and $80 \%$ of people, respectively, feel comfortable [13]. The expectancy factor is included as an additional compensation for the maximum acceptable ePMV value in warm climates, and based on these assumptions the expectancy factor can be estimated at 0.7. The Finger's Equation and all equations that used for calculating $t_{c l}, f_{c l}$, $p_{a}$ and $h_{c}$ were written in the UDF file (User-Define-Function) and linked with ANSYS FLUENT.

In this study, the main objective was to quantify the wind speed on the human thermal comfort index (PMV). First, the accuracy and reliability of the CFD model were verified using the measurements of flow over and through a cross-ventilated building model in a boundary layer wind tunnel (Ohba et al.[14]). Second, the impact of wind speed on the thermal comfort index was evaluated through the simulations through a combination of the low Reynolds number (LRNM) with Steady Reynolds Averaged Navier-Stokes (RANS) RNG k- $\varepsilon$ modelling approaches and the thermal comfort index model. The findings from this study are expected to improve the understanding, and increase knowledge, of the impact of these parameters on human thermal comfort indices in residential buildings. 


\section{BUILDING GEOMETRY}

Fig. 1(a) illustrates the geometry model that was used to evaluate the potential for natural ventilation to allow for the suitable thermal comfort of the occupants of an isolated family house in Iraq. The layout consisted of five rooms: kitchen (A), sitting room (B), living room (C), and two bedrooms (D and E), which represents an average house for an average family in Iraq [14]. The height of the building was $\mathrm{H}$, with base dimensions of $(3.33 \times 2.66) \mathrm{H}$, whilst the thickness of the walls was set as $0.067 \mathrm{H}$. The length of the building was less than the maximum length suggested by Amos-Abanyie et al. [4] and Chu and Chiang [5], to obtain effective wind-driven cross ventilation. There were two square openings in the front wall and two openings at the rear of the building of size $0.2 \mathrm{H}$; details of the locations of these openings are provided in Fig. 1(b). The wind speeds assumed were 7, 5 and $3 \mathrm{~m} / \mathrm{s}$, and simulations were based on the height of the building $\left(U_{\text {ref }}\right)$ with an angle of incidence of $0^{\circ}$.

\section{CFD MODEL VALIDATION}

This study used the steady Reynolds-averaged Navier-Stokes (RANS) equations to model the flow-field, combined with the low-Reynolds number modelling (LRNM). The Renormalization Group RNG k- $\varepsilon$ model was chosen over the other variants of the two equation turbulence models because of its popularity for modelling indoor air movement. In addition, the equation for energy conservation is solved to calculate the temperature variation within the computational domain. The accuracy of the CFD simulation was evaluated by comparing the predicted flow field with the experiments conducted by Ohba et al. [14], on a cross-ventilation building model. The experiment was conducted in a wind tunnel of $(1.2 \times 1.0) \mathrm{m}$ cross section and a length of $1.4 \mathrm{~m}$. The model had a height of $15 \mathrm{~cm}$, measuring 1:2:2 (Fig. 2(a)). The front and rear openings of the building model were placed perpendicular to the approaching flow, and had the same dimensions $(6 \mathrm{~cm}$ in width and 3 $\mathrm{cm}$ in height). The reference mean wind speed $\left(U_{r e f}\right)$ was maintained at $7.0 \mathrm{~m} / \mathrm{s}$ at the edge of the model. As shown in Fig.2b, the pressure coefficient profiles at the middle of the inlet and outlet opening obtained from the steady RANS simulation were compared against the experimental data determined by Ohba et al. [14]. The performance of the steady RANS model was satisfactory, and the comparison between the two results was in reasonably good agreement.

a)

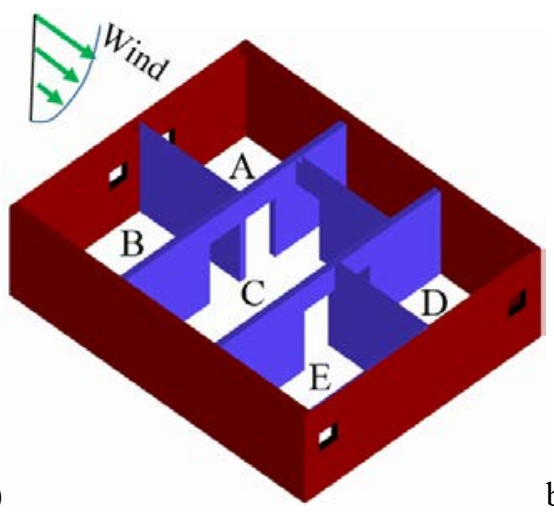

b)

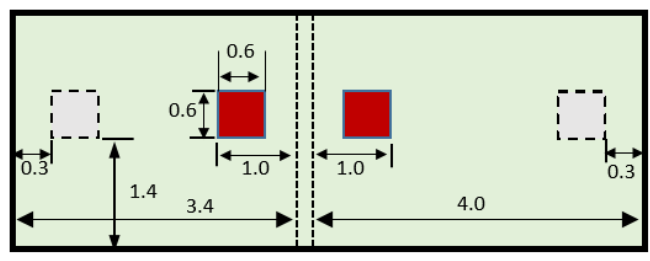

Figure 1: Building geometry. (a) Perspective view; and (b) Front view (dimensions in meters). 


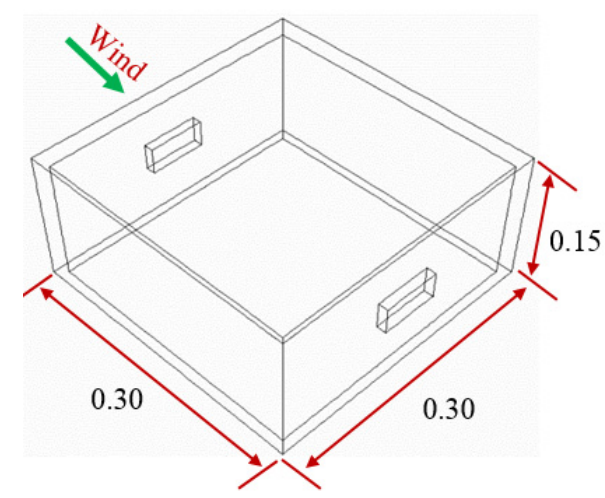

a)

Figure 2: CFD case validation. (a) Validation geometry and; (b) Comparison between the CFD and experiment results.

\section{COMPUTATIONAL MODEL SETTING AND PARAMETERS}

The computational domain was constructed based on the guidelines in wind engineering, and had dimensions $(23.33 \times 5 \times 12.6) \mathrm{H}$. The building was set inside the duct, the blockage ratio was $4.2 \%$, and the distance between the outflow boundary and the building was $15 \mathrm{H}$, which is enough to allow the flow to redevelop in the wake region. The numerical grid used consisted of around $6 \times 10^{6}$ hexahedral computational cells, with a fine mesh structured near the walls of minimum grid spacing $0.005 \mathrm{H}$, whereas a coarse mesh was used away from the walls. A grid independence study for the basic case was conducted to ensure that the results were independent of the mesh resolution; a logarithmic inlet velocity profile was employed at the inlet of the duct, with the equations of turbulent kinetic energy and specific dissipation rate equations reported in the previous study by the current authors [14]. The surfaces of the building and the ground of the domain were modelled as a no-slip boundary, while a symmetric boundary condition was applied to the two sides and top of the domain, and outflow boundary conditions were specified at the end of the domain. The walls in the house geometry were assumed adiabatic. A uniform temperature of $28^{\circ} \mathrm{C}$ was specified as the outdoor thermal condition and was applied to the inlet boundary of the duct. The heat generation was uniformly applied to the floor of all the rooms as a boundary condition, and was assumed as $100 \mathrm{~W} / \mathrm{m}^{2}$ for a family house with several occupants using several electrical appliances at any given time. For incompressible flow, the pressure-based solver was used in the current study. The SIMPLEC scheme was imposed as the pressure-velocity coupling method.

\section{RESULTS AND DISCUSSION}

The impact of outdoor wind speed on indoor thermal comfort was studied by choosing the wind speeds $\left(U_{\text {ref }}\right)$ at building height references, $\mathrm{H}$ of 3,5 and $7 \mathrm{~m} / \mathrm{s}$. The temperature was fixed to $28^{\circ} \mathrm{C}$. The numerical results are presented and compared in terms of average velocity, followed by extended predicted mean vote (ePMV) values for metabolic rates (heat production), $\mathrm{M}$ of $58 \mathrm{~W} / \mathrm{m}^{2}$ (seated), and $70 \mathrm{~W} / \mathrm{m}^{2}$ (standing). The thermal resistance for typical clothing insulation under summer condition was set as being equal to $0.5 \mathrm{clo}$, the relative humidity was fixed at $50 \%$ with zero external work (W). The ePMV contours 
of a horizontal plan were found at a height of $1.0 \mathrm{~m}$ from the ground of the building for the seated case and $1.5 \mathrm{~m}$ for the standing case, as shown in Fig. 5, as these levels are commonly used in assessing thermal comfort in residential buildings.

Fig. 3 showed the average velocity and ePMV on the working plane of $1 \mathrm{~m}$ above the floor (seated level). Under a wind velocity of $7 \mathrm{~m} / \mathrm{s}$, all rooms were found to have a high indoor average velocity $(0.45 \mathrm{~m} / \mathrm{s})$ and acceptable thermal comfort with an ePMV of around 0.85 , whilst at the reference velocity $3 \mathrm{~m} / \mathrm{s}$ the ePMV index increased to around 1.7 which is the undesired condition for the occupants. Regarding standing plane, the ePMV index was close to the seated level (around 0.87) as shown in Fig. 4, although the simulation predicted higher average velocity in this level at the reference velocity $7 \mathrm{~m} / \mathrm{s}$. On the other hand, at the reference velocity $3 \mathrm{~m} / \mathrm{s}$ the ePMV decreased noticeably to 1.3 at the standing level and to 1 at $U_{\text {ref }}=5 \mathrm{~m} / \mathrm{s}$, which means that this level can stay in desired thermal condition in a wide range of wind speed.

In addition, Fig. 3 showed that the difference between the front rooms (A and B) and rear rooms ( $\mathrm{D}$ and $\mathrm{E}$ ) in values of ePMV is less than $40 \%$ at the reference velocity $7 \mathrm{~m} / \mathrm{s}$, whereas it showed a significant difference at a specific wind velocity of $3 \mathrm{~m} / \mathrm{s}$, being more than $80 \%$. It can also be seen that the difference in thermal index (ePMV) for the front rooms is higher than that for the rear rooms by $56 \%$ at the reference velocity of $5 \mathrm{~m} / \mathrm{s}$. This is because the role of buoyancy effects becomes more influential at low velocities, thus causing an increase in temperature and ePMV.

The thermal comfort condition for the standing activities $(1.2 \mathrm{~m})$ in all rooms at a height of $1.5 \mathrm{~m}$ was also analysed, and showed the same trend as the seated level, but with less difference between the front rooms and rear rooms as shown in Fig. 4. In this instance, however, the differences in ePMV between front rooms and rear rooms were $60 \%, 43 \%$ and $40 \%$ at the reference velocities of 7,5 and $3 \mathrm{~m} / \mathrm{s}$, respectively. The reason for this was due to this level being located near to the level openings position, and the flow had a greater impact on ePMV than a plane located far from the level of openings. Therefore, the average velocities for the standing plane are higher than the average velocities for the seating plane by $14 \%, 20 \%$ and $27 \%$ for reference velocities of 3,5 , and $7 \mathrm{~m} / \mathrm{s}$, respectively. However, when the reference speed was set at $7 \mathrm{~m} / \mathrm{s}$, the values of the ePMV for the seated and the standing plans are almost identical whilst the significant differences are remarked at the reference velocities of $5 \mathrm{~m} / \mathrm{s}$ and $3 \mathrm{~m} / \mathrm{s}$ of $18 \%$ and $30 \%$, respectively. This means that at high wind speeds the human thermal comfort zone (between seated level and standing level) will be at almost the same thermal conditions. Generally, it can be concluded that crossventilation is an effective means by which to provide a thermally comfortable environment in this type of building, as long as the wind speed is at relatively high speed.

The thermal contour plot can provide more useful information for the designers when applying natural ventilation as an example (Figs 5 and 6). Although the average values of the ePMV are in the acceptance range of rooms D and E of the seated plane (Fig. 5(a)), the contour plot shows two zones (colored red) inside these rooms with high ePMV values $(\approx 2)$, which will cause discomfort for any occupants. The average velocities contours of this plane showed that the air velocity is close to zero inside these zones as shown in Fig. 7.

Regarding the standing plane (Fig. 5(b)), these same two zones are more comfortable (ePMV $\approx 1.2$ ), therefore the occupants should avoid these zones when either sleeping or when seated. In addition, the area around the two zones (coloured red and yellow) in the PMV contours (Fig. 5(a)) increased with decreasing wind speed in the seated plane (Fig. 6(a)). For instance, the area of the discomfort zones in rooms $\mathrm{D}$ and $\mathrm{E}$ was very small when the $U_{\text {ref }}$ was $7 \mathrm{~m} / \mathrm{s}$, and increased noticeably when the $U_{r e f}$ was $5 \mathrm{~m} / \mathrm{s}$ and the same trend occurred in 
room C. In general, the figure shows that the implementation of cross ventilation in this kind of building can create a thermally comfortable indoor environment, but with low air velocities a natural ventilation for the cooling purpose becomes insufficient to provide thermal comfort, especially in the rear rooms $\mathrm{E}$ and $\mathrm{D}$.
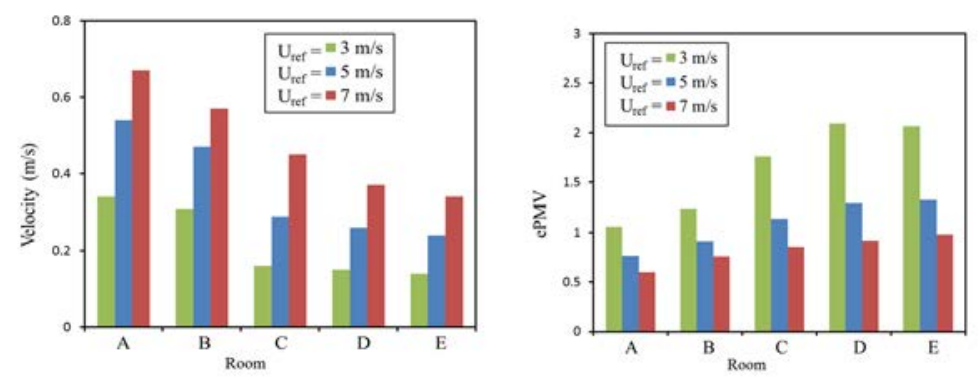

Figure 3: Average velocity and ePMV of rooms in the seated level at different reference velocities.
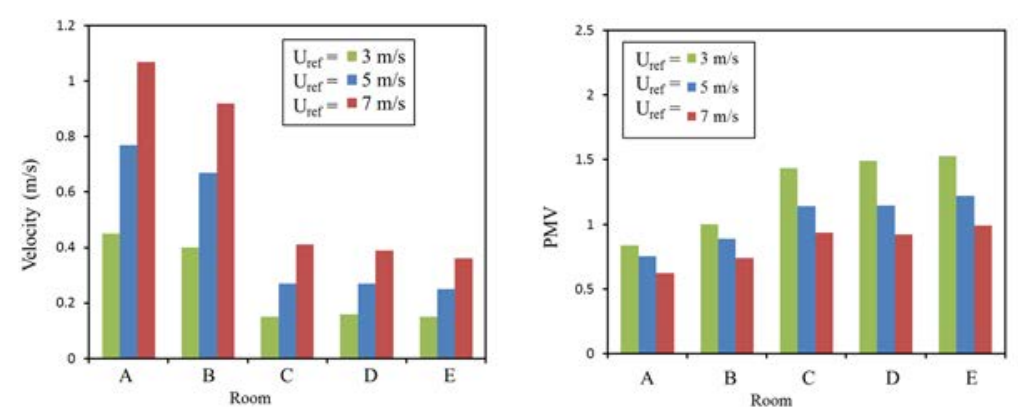

Figure 4: Average velocity and ePMV of rooms in the standing level at different reference velocities.

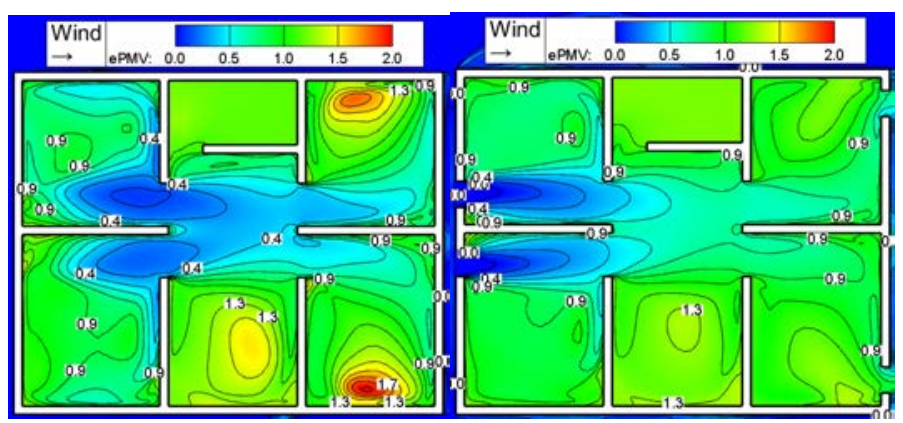

a)

b)

Figure 5: ePMV distributions in the working plane at $U_{\text {ref }}=7 \mathrm{~m} / \mathrm{s}$; (a) $\mathrm{y}=1 \mathrm{~m}$ and (b) $\mathrm{y}=$ $1.5 \mathrm{~m}$. 


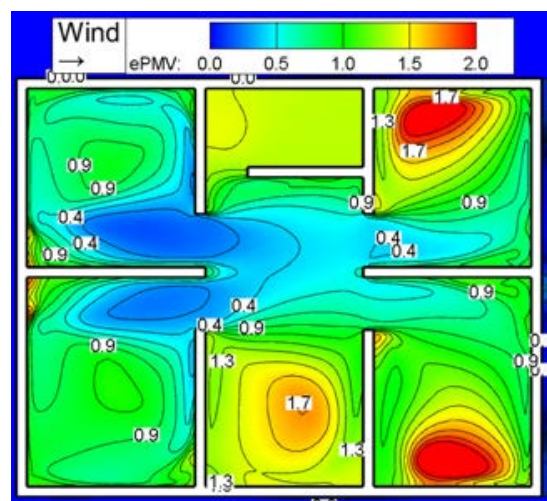

a)

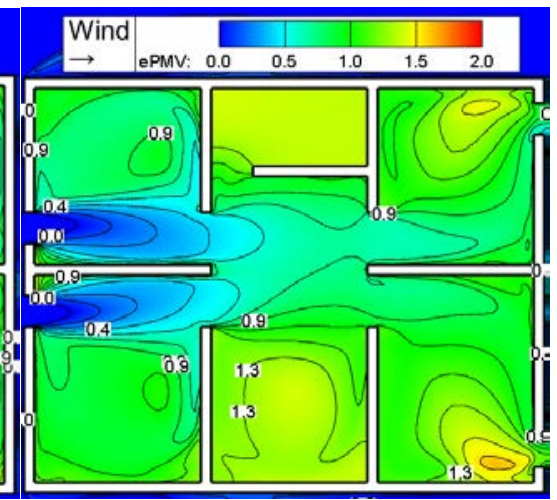

b)

Figure 6: ePMV distributions in the working plane at $U_{\text {ref }}=5 \mathrm{~m} / \mathrm{s}$; (a) $\mathrm{y}=1 \mathrm{~m}$ and (b) $y=$ $1.5 \mathrm{~m}$.

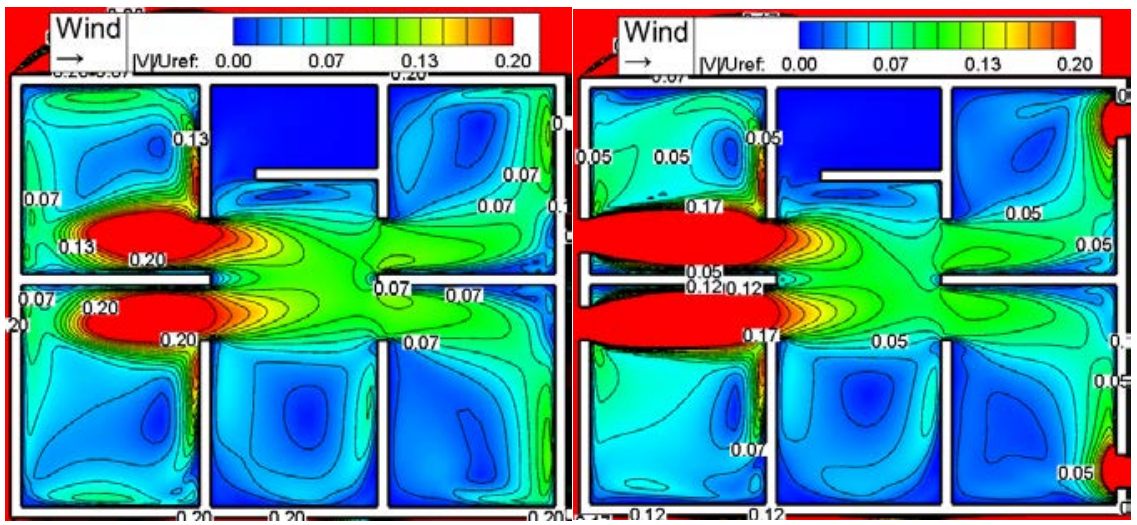

Figure 7: Contours of dimensionless mean velocity magnitude $(|\mathrm{V}| /$ Uref $)$ in the working plane at Uref $=7 \mathrm{~m} / \mathrm{s}$; (a) $\mathrm{y}=1 \mathrm{~m}$ and (b) $\mathrm{y}=1.5 \mathrm{~m}$.

\section{CONCLUSION}

This study has examined the changes in thermal comfort inside a small residential building when the outdoor wind speed changes by using the steady RANS method. Since the thermal comfort was analysed with regards to the ePMV index, the above predictions show that the wind speed has a major influence on the indoor thermal comfort under a given ventilation strategy. The study concludes that thermal comfort can be more active in this type of building if the wind speed is relatively high. The contour plot showed the places where it would be more comfortable for any occupants to perform their daily activities. To achieve the desired level of human thermal comfort, it will be necessary to control the influence of the wind, e.g. through an appropriate arrangement of ventilation openings. Investigating indoor thermal comfort in a multi-zone building could give the designers valuable information regarding more energy efficient designs in naturally ventilated buildings. 


\section{REFERENCES}

[1] Xing, Y., Hewitt, N. \& Griffiths, P., Zero carbon buildings refurbishment a hierarchical pathway. Renewable and sustainable energy reviews, 15 pp. 3229-3236, 2011.

[2] Ahmed, A.Q. \& Gao, S., Numerical investigation of height impact of local exhaust combined with an office work station on energy saving and indoor environment. Building and Environment, 122, pp. 194-205, 2017.

[3] Prakash, D. \& Ravikumar, P., Analysis of thermal comfort and indoor air flow characteristics for a residential building room under generalized window opening position at the adjacent walls. International Journal of Sustainable Built Environment, 4, 42-57, 2015.

[4] Amos-Abanyie, S., Koranteng, C. \& Apeatse, K., An evaluation of the effects of external landscaping elements on indoor airflow rate and patterns using computational fluid dynamics. European Scientific Journal, 10, 2014.

[5] Chu, C.R. \& Chiang, B.F., Wind-driven cross ventilation in long buildings. Building and Environment, 80 pp. 150-158, 2014.

[6] Hawendi, S. \& Gao, S., Impact of windward inlet-opening positions on fluctuation characteristics of wind-driven natural cross ventilation in an isolated house using LES. International Journal of Ventilation, pp. 1-27, 2017.

[7] Hassan, M., Guirguis, N., Shaalan, M. \& El-Shazly, K., Investigation of effects of window combinations on ventilation characteristics for thermal comfort in buildings. Desalination, 209, pp. 251-260, 2007.

[8] Gao, C. \& Lee, W., Evaluating the influence of openings configuration on natural ventilation performance of residential units in Hong Kong. Building and environment, 46, pp. 961-969, 2011.

[9] Stavrakakis, G., Zervas, P., Sarimveis, H. \& Markatos, N., Optimization of windowopenings design for thermal comfort in naturally ventilated buildings. Applied Mathematical Modelling, 36, pp. 193-211, 2012.

[10] Koranteng, C., Essel, C. \& Nkrumah, J., Passive Analysis of the Effect of Window Size and Position on Indoor Comfort for Residential Rooms in Kumasi, Ghana. International Journal on Architecture Science. 2, 2015.

[11] Ashrae, A.S., Standard 55-2013. Thermal Environmental Conditions for Human Occupancy. 2013.

[12] Fanger, P.O., Thermal comfort. Analysis and applications in environmental engineering. Thermal comfort Analysis and applications in environmental engineering, 1970.

[13] Abiodun, O.E., Examination of thermal comfort in a naturally ventilated hostel using PMV-PPD model and field survey, 3(8) 2014.

[14] Ohba, M., Irie, K. \& Kurabuchi, T., Study on airflow characteristics inside and outside a cross-ventilation model, and ventilation flow rates using wind tunnel experiments. Journal of Wind Engineering and Industrial Aerodynamics, 89 pp. 1513-1524, 2001.

[15] Hawendi, S. \& Gao, S., Impact of an external boundary wall on indoor flow field and natural cross-ventilation in an isolated family house using numerical simulations. Journal of Building Engineering, 10 pp. 109-123, 2017.

[16] Hawendi, S. \& Gao, S., Investigation of Opening Positions on the Natural Ventilation in a Low-Rise Building by CFD Analysis. In Proceedings of the 3rd International Conference on Fluid Flow, Heat and Mass Transfer (FFHMT16, Paper No. 151) Ottawa, Canada. 